\title{
A REVISÃO DA LEI BRASILEIRA DE INCLUSÃO À PESSOA COM DEFICIÊNCIA (LEI N.13146/15) E AS FALHAS NA SUA APLICAÇÃ̃ ${ }^{1}$
}

THE REVISION OF THE BRAZILIAN LAW OF INCLUSION TO PERSONS WITH DISABILITIES (LAW N.13146 / 15) AND THE FAILURES IN ITS APPLICATION

Beatriz Gomes SANTANNA ${ }^{2}$

Ana Cristina GOMES ${ }^{3}$

ISSUE DOI: $10.21207 / 2675-0104.2019 .917$

\begin{abstract}
RESUMO
A Convenção Internacional dos Direitos Humanos, instituída pela Organização das Nações Unidas ONU, introduziu na ordem mundial a universalidade, a indivisibilidade e a interdependência dos direitos, que em seu artigo $1^{\circ}$, primou pela igualdade de dignidade e de direitos. Desde então, a ordem internacional passou a desenvolver legislações compatíveis com a nova determinação de promoção da igualdade a todos os seres humanos, mas, principalmente, com olhar voltado aos grupos vulneráveis. Nesse contexto, o presente trabalho tem o objetivo de analisar e discutir as alterações promovidas com o advento do da Lei $\mathrm{n}^{\circ}$ 13.146/2015 intitulada Lei Brasileira de Inclusão - Estatuto da Pessoa com Deficiência - e suas consequências. Inicialmente, será abordado o princípio da dignidade humana, por ser um dos alicerces da emancipação dos direitos das minorias. Posteriormente, será analisado o
\end{abstract}

\footnotetext{
${ }^{1} \mathrm{O}$ presente artigo sintetiza a monografia de conclusão da pesquisa, realizada para o Programa Interno de Bolsas de Iniciação Científica (PIBIC 2018-2019) da Faculdade de Direito de Franca (FDF), Franca/SP.

${ }^{2}$ Discente da Faculdade de Direito de Franca (FDF), Franca/SP. Bolsista do Programa Interno de Bolsas de Iniciação Científica (PIBIC 2018-2019).

${ }^{3}$ Graduada em Direito pela Universidade Estadual Paulista "Julio de Mesquita Filho", Mestre em Direito pela Universidade Estadual Paulista "Julio de Mesquita Filho", doutoranda pela Universidad de Salamanca na Escuela de Doctorado - Estado de Derecho y Gobernanza Global, professora colaboradora da Faculdade de Direito de Franca.
} 
Estatuto da Pessoa com Deficiência, a capacidade civil e a alterações do Código Civil de 2002. Por fim, apontar a manutenção ou não do instituto da interdição Pós-Estatuto da Pessoa com Deficiência.

Palavras-chave: Inclusão; Autismo; Convenção sobre os Direitos das Pessoas com Deficiência.

\section{ABSTRACT}

The United Nations International Convention on Human Rights, established by the United Nations, introduced the universality, indivisibility and interdependence of rights into the world order, which in its first article was based on equality of dignity and rights. . Since then, the international order has begun to develop legislation compatible with the new determination to promote equality for all human beings, but especially with a focus on vulnerable groups. In this context, the present work aims to analyze and discuss the changes promoted with the advent of Law No. 13.146 / 2015 entitled Brazilian Inclusion Law - Statute of the Disabled - and its consequences. Initially, the principle of human dignity will be addressed, as it is one of the foundations of the emancipation of minority rights. Subsequently, the Disability Statute, civil capacity and amendments to the 2002 Civil Code will be analyzed. Finally, the maintenance or not of the Post-Statute Disability Interdiction Institute should be maintained.

Keywords: Inclusion; Autism; Convention on the Rights of Persons with Disabilities.

\section{INTRODUÇÃO}

É inegável a importância legislativa da Lei $n^{\circ}$ 13.146/2015 perante a sociedade brasileira, posto que está entrelaçada com o art. $5^{\circ}$, caput, da CF/88 em que se estabelece que "'todos são iguais perante a lei sem distinção de qualquer natureza.', enfatizando a área educacional das pessoas com deficiência tangenciadas pela lei em tela, a fim de que em prática todos tenham seu direito a educação tutelado.

Assim, o presente estudo justifica-se pela necessidade de demonstrar as falhas na aplicação desta legislação, com enfoque na inclusão social das pessoas com deficiência portadoras do autismo - ou TEA - na área da educação, e os desafios dos órgãos educacionais e seus profissionais, embasados na Constituição Federal com o princípio da igualdade art. $5^{\circ}$, caput, I, em que intitula que todos têm direito ao acesso à educação. Também será dado foco ao princípio da dignidade humana, sendo este a base do surgimento da legislação em tela.

Ao tratar sobre a lei supracitada, deve-se destacar a importância da atuação do Estado de forma positiva, sendo a Lei $\mathrm{n}^{\circ}$ 13.146/15 um mecanismo estatal para cumprir seu dever de fomentação dos direitos fundamentais.

O direito à educação, disposto no art. 27 da Lei $n^{\circ}$ 13.146/15, é exposto como garantia que todas as pessoas com deficiência têm direito a educação ao longo de todo período de sua vida, assegurando seu máximo desenvolvimento possível. 
Embora a lei tenha bons fundamentos e ideais bem intitulados, ela se mostra falha em certos aspectos, o que a torna totalmente ineficaz e sem eficiência, pois não se trata apenas de fornecer, colocar uma criança ou adolescente com o transtorno do espectro autista em uma sala de aula, trata-se de todo um conjunto em que na maioria das vezes é esquecido.

O principal problema é que a lei é criada visando amparar uma generalidade de deficientes, porém cada desigual deveria ser tratado desigualmente, no sentido de que um autista tem necessidades diferentes de um cadeirante, tornando o rol de auxilio que deve ser fornecido diferente também. Ao se aplicar um protocolo geral para indivíduos diferentes encontramos pormenores que geram a inviabilização do principal quesito da lei que é assegurar o máximo desenvolvimento desse indivíduo.

\section{O PRINCÍPIO DA DIGNIDADE HUMANA}

Os direitos das minorias em geral possuem como um de seus alicerces principais o princípio da dignidade humana, fazendo-se assim necessária uma abordagem de tal princípio para uma melhor compreensão das dimensões que o presente trabalho irá atingir.

O princípio da dignidade humana foi elevado, em decorrência do neoconstitucionalismo, movimento pós-II guerra, à categoria de valor fundamental da constituição, como uma espécie de sobre-princípio, devendo as demais normas, portanto, a ele prestar obediência. ${ }^{4}$

Assim, pode-se apontar quanto a esta nova leitura teórica: De forma bastante singela, podemos conceituar o neoconstitucionalismo como uma nova forma de se interpretar o Direito a partir da valorização dos direitos humanos, cuja expressão máxima são os direitos fundamentais constantes nas Cartas Políticas de cunho democrático.

(...) Eis as características: supremacia do texto constitucional; garantia, promoção e preservação dos direitos humanos; força normativa dos princípios constitucionais; constitucionalização do Direito; ampliação da jurisdição constitucional. ${ }^{5}$

\footnotetext{
${ }^{4}$ MENDES, Gilmar Ferreira; COELHO, Inocêncio Mártires; BRANCO, Paulo Gustavo Gonet. Curso de Direito Constitucional. 4. ed. São Paulo: Saraiva, 2009.

${ }^{5}$ GUTIERREZ SOBRINHO, Emílio. Neoconstitucionalismo: apontamentos teóricos. Revista Jus Navigandi, ISSN 1518-4862, Teresina, ano 17, n. 3319, 2 ago. 2012. Disponível em: https://jus.com.br/artigos/22345/aspectos-teoricos-do-movimento-neoconstitucional Acesso em 03 set. 2019.
} 
Essa visão humanista foi inaugurada no Direito brasileiro pela Constituição Federal de 1988, sendo consolidada tal perspectiva com a internalização no direito interno da Convenção Internacional sobre os Direitos da Pessoa com Deficiência, por meio do Decreto Legislativo $\mathrm{n}^{\circ}$ 186, de 09 de julho de 2008 e por sua promulgação pelo Decreto Executivo $\mathrm{n}^{\circ} 6.949$, de 25 de agosto de 2009 que possui hierarquia constitucional, sobrepondo-se às normas infraconstitucionais estabelecidas pelo Código Civil de 2002, diante de sua aprovação conforme o quórum de emenda constitucional, previsto no art. $5^{\circ}, \S 3^{\circ}, \mathrm{CF}$.

Quanto a este ponto, destaca Correia de Andrade:

O princípio da dignidade está contido, ainda que sob roupagem diversa, em outros dispositivos constitucionais, como o artigo $3^{\circ}$, que estabelece, dentre os objetivos fundamentais da República Brasileira, a construção de uma "sociedade livre, justa e solidária" (inciso I). Liberdade, justiça e solidariedade são valores que estão vinculados, indissociavelmente, à dignidade humana, porque constituem condições para a sua efetivação. O mesmo dispositivo constitucional indica, como outro objetivo fundamental, "promover o bem de todos, sem preconceitos de origem, raça, sexo, cor, idade e quaisquer outras formas de discriminação" (inciso IV). ${ }^{6}$

Todos são merecedores de igual consideração por parte do Estado e de seus semelhantes. Portanto, a dignidade da pessoa humana é preocupação da $\mathrm{CF} / 88$ em diversos setores da vida social, fato que demonstra a importância atual deste princípio.

Tratando do tema, Andrade7 assevera complexidade inerente ao conceito de dignidade torna dificultosa a determinação do seu conteúdo. $\mathrm{O}$ que venha a compor o conceito de dignidade é algo que não pode ser definido abstratamente, mas apenas em concreto, à luz de um determinado ordenamento jurídico e dos influxos históricos e culturais de cada sociedade.

Sendo assim, pode a dignidade ser entendida como o respeito ao núcleo básico dos direitos pessoais do indivíduo.

A própria ideia de Direito se confunde com a necessidade de segurança. Necessidade de dar estabilidade e clareza às relações sociais, de uma maneira que permita ao homem estabelecer ordem na vida social, é um dos escopos primordiais do Direito.

\footnotetext{
${ }^{6}$ ANDRADE, André Gustavo Corrêa de. O princípio fundamental da dignidade humana e sua concretização judicial. Disponível em: http://www.tj.rj.gov.br/institucional/dir_gerais/dgcon/pdf/artigos/direi_const/o_pr. Acesso em 03 set. 2019.

${ }^{7}$ Idem.
} 
(...) Isso porque não é possível imaginar a liberdade, a dignidade da pessoa humana, a democracia, a justiça, numa sociedade onde o caos impera. Não que tais valores sejam de menor importância. Muito ao contrário. Na verdade, são eles fundamentais. Contudo, eles nada são se em uma determinada sociedade não houver um grau de segurança nas relações humanas sociais. ${ }^{8}$

É nesse contexto social e normativo, pois, que deve se enquadrar a análise da evolução do instituto da incapacidade jurídica do deficiente, tendo em vista que o estudo da mudança legislativa - tendo como base o texto original dos artigos $3^{\circ}$ e $4^{\circ}$ do código civil até a atual reforma causada pelo Estatuto da Pessoa com Deficiência - permitirá o alcance de um nível superior de compreensão sobre o tema.

A Lei $n^{\circ}$ 13.146/15 teve inicio com o Projeto Lei $n^{\circ}$ 6/2003, realizado pelo senador Paulo Paim, tendo por objetivo concretizar a acessibilidade e condição de acesso para utilização, com segurança e autonomia por pessoa com deficiência de transportes, informações, educação, saúde entre outros serviços e locais urbanos.

Assim, discorre o artigo $1^{\circ}$ desta legislação em tela:

"É instituída a Lei Brasileira de Inclusão da Pessoa com Deficiência (Estatuto da Pessoa com Deficiência), destinada a assegurar e a promover, em condições de igualdade, o exercício dos direitos e das liberdades fundamentais por pessoa com deficiência, visando à sua inclusão social e cidadania."

Tem como fonte basilar a Convenção sobre os Direitos das Pessoas com Deficiência, visto que sua adoção é de cunho facultativo, o Brasil resolveu abarcar tal Convenção, e a ratificou por meio do Congresso Nacional com o Decreto Legislativo $n^{\circ} 186$, de 9 de julho de 2008,

\footnotetext{
${ }^{8}$ ALMEIDA, João Alberto de; SOUZA BRITO, Thiago Carlos de. O princípio da segurança jurídica e suas implicações na relativização da coisa julgada. Disponível em: https://www.direito.ufmg.br/revista/index.php/revista/article/viewFile/130/121 . Acesso em 03 ago. 2019.

${ }^{9}$ BRASIL. Lei №. 13.146/2015. Lei Brasileira de Inclusão da Pessoa com Deficiência. Disponível em: http://www.planalto.gov.br/ccivil 03/ ato2015-2018/2015/lei/113146.htm. Acesso em 03 set. 2019.
} 
adequando a lei pátria ao pactuado na Convenção de Direitos Humanos sobre os Direitos das Pessoas com Deficiência de Nova York de 2007. ${ }^{10}$

Assim como a legislação em tela, assegurou a oferta de sistema educacional inclusivo em todos os níveis e modalidades de ensino. Estabeleceu ainda a adoção de um projeto pedagógico que institucionaliza o atendimento educacional especializado. ${ }^{11}$

$\mathrm{O}$ artigo $2^{\circ}$ da Lei $\mathrm{n}^{\circ} 13.146 / 2015$ tece o conceito do que é ser deficiente físico:

\begin{abstract}
Considera-se pessoa com deficiência aquela que tem impedimento de longo prazo de natureza física, mental, intelectual ou sensorial, o qual, em interação com uma ou mais barreiras, pode obstruir sua participação plena e efetiva na sociedade em igualdade de condições com as demais pessoas. ${ }^{12}$
\end{abstract}

Consta ressaltar a importância da Convenção sobre os Direitos das Pessoas com Deficiência, posto que segundo dados do IBGE, 14,5\% da população declarou possuir algum tipo de deficiência. ${ }^{13}$

Com base nestes dados, a palavra "inclusão" se torna densa e necessária, visto que a tutela do estado deve buscar linhas antidiscriminatórias para que a liberdade e a efetiva inserção dos portadores de alguma deficiência na sociedade se concretize, assim, a legislação em tela, coíbe certos comportamentos dos cidadãos, como se é tratado no artigo $4^{\circ}$ da Lei $n^{\circ} 13.146 / 2015$ que dispõe que:

Toda pessoa com deficiência tem direito à igualdade de oportunidades com as demais pessoas e não sofrerá nenhuma espécie de discriminação.

$\S 1^{\circ}$ Considera-se discriminação em razão da deficiência toda forma de distinção, restrição ou exclusão, por ação ou omissão, que tenha o propósito ou o efeito de prejudicar, impedir ou anular o reconhecimento ou o exercício dos direitos e das liberdades

\footnotetext{
${ }^{10}$ LEITE, Flávia Piva Almeida. A Convenção sobre os Direitos das Pessoas com Deficiência: Amplitude Conceitual. Revista de Direito Brasileira. RDBras, $3^{\mathrm{a}}$ edição, 2012, p. 36.

${ }^{11}$ AGÊNCIA SENADO. Lei Brasileira de Inclusão completa um ano com avanços na educação. 2016.

Disponível em: < https://www12.senado.leg.br/noticias/materias/2016/07/01/lei-brasileira-deinclusao-completa-um-ano-com-avancos-na-educacao > Acesso em 03 set. 2019.

${ }^{12}$ BRASIL. Lei $N^{\circ}$. 13.146/2015. Lei Brasileira de Inclusão da Pessoa com Deficiência. Disponível em: http://www.planalto.gov.br/ccivil_03/_ato2015-2018/2015/lei/113146.htm. Acesso em 03 set. 2019.

${ }^{13}$ BRASIL. A Convenção sobre os Direitos das Pessoas com Deficiência Comentada. 2008. Disponível em: <https://www.governodigital.gov.br/documentos-earquivos/A\%20Convencao\%20sobre \%20os\%20Direitos\%20das\%20Pessoas\%20com\%20Deficiencia $\% 20$ Comentada.pdf > Acesso em 03 set. 2019.
} 
Assim, a Convenção sobre os Direitos das Pessoas com Deficiência é de suma importância quando coligada ao nosso aparato normativo por meio da legislação em vigência supracitada, posto que o objetivo central é permitir a emancipação dos cidadãos, por meio da consolidação da independência como uma garantia, tencionando inclusive um acentuado aumento da inclusão dos portadores de deficiências na área educacional.

\subsection{MODIFICAÇÕES NO CÓDIGO CIVIL}

Antes de apresentar as modificações trazidas ao regime das incapacidades, regido pelo Código Civil, faz-se necessário fazer um breve panorama do instituto da personalidade e da capacidade civil.

\subsubsection{PERSONALIDADE CIVIL}

A máxima de que não existe sociedade sem direito, nem direito sem sociedade, apresenta em si a pessoa como sujeito de direito. Ser sujeito de direito significa que, uma vez que as pessoas constituem a sociedade, elas se relacionam entre si criando direitos e assumindo obrigações. Nesse mesmo entendimento, preconiza o Código Civil de 2002, em seu artigo $1^{\circ}$, quando prevê que "toda pessoa é capaz de direitos e deveres na ordem civil." $" 15$

A personalidade, portanto, será "o conjunto de características e atributos da pessoa humana, considerada objeto de proteção privilegiada por parte do ordenamento [...]"16. Esse privilégio nem sempre foi passível de todo ser humano, em outras épocas, por exemplo, os escravos não eram

\footnotetext{
${ }^{14}$ BRASIL. Lei No ${ }^{\circ}$ 13.146/2015. Lei Brasileira de Inclusão da Pessoa com Deficiência. Disponível em: http://www.planalto.gov.br/ccivil 03/_ato2015-2018/2015/lei/113146.htm. Acesso em 03 set. 2019.

${ }^{15}$ BRASIL. Lei $\mathrm{n}^{\circ}$ 10.406, de 10 de janeiro de 2002. Institui o Código Civil. 2002. Disponível em: http://www.planalto.gov.br/ccivil 03/leis/2002/L10406.htm. Acesso em 03 set. 2019.

${ }^{16}$ MARTINS, S. P. O Estatuto da Pessoa com Deficiência e as alterações jurídicas relevantes no âmbito da capacidade civil. Revista dos Tribunais, v. 974, p. 225-243, dez. 2016.
} 
considerados pessoas e, dessa forma, não eram detentores de personalidade.

$\mathrm{O}$ ordenamento pátrio, auxiliado pela medicina, fixa como momento de início da personalidade, aquele em que ocorre o nascimento com vida, no instante em que se dá a respiração extrauterina pulmonar.

\subsubsection{CAPACIDADE CIVIL}

O artigo $1^{\circ}$ do Código Civil de 2002, estabelece que toda pessoa, desde o seu nascimento com vida, é dotada de capacidade civil. Essa capacidade confere o limite da personalidade e se divide em capacidade jurídica ou de direito e capacidade de exercício ou de fato.

Por sua vez, a capacidade de exercício está diretamente ligada à capacidade da pessoa de agir por si própria, autonomamente, se valendo de um mínimo de discernimento, para o exercício de direitos patrimoniais, sem a necessidade de representantes ou assistentes. É, portanto, "a possibilidade de praticar atos com efeito jurídico, adquirindo, modificando ou extinguindo relações jurídicas". ${ }^{17}$

Nesse sentido, a pessoa pode possuir capacidade jurídica e não possuir capacidade de exercício, pois a impossibilidade de manifestação da vontade ou falta de compreensão de determinados atos impede a atuação da capacidade de exercício.

O Código Civil, na sua Parte Geral, distingue as incapacidades de exercício em absoluta e relativa. Incapacidade absoluta será aquela em que a pessoa não possui condições de exercer pessoalmente todos os atos da vida civil devendo, portanto, ser representada pelos pais ou por outros sujeitos, conforme legalmente previsto. Já na incapacidade relativa a pessoa possui condições de exercer determinados atos da vida civil, sendo necessária a assistência dos pais ou de outras pessoas, consoante previsão legal.

As hipóteses de incapacidade absoluta estavam assim previstas na redação originaria do artigo $3^{\circ}$ do Código Civil ${ }^{18}$, in verbis:

Art. $3^{\circ}$ São absolutamente incapazes de exercer pessoalmente os atos da vida civil:

I - os menores de 16 (dezesseis) anos;

\footnotetext{
${ }^{17}$ AMARAL, F. Direito civil: introdução. Rio de Janeiro: Renovar, 2003.

${ }^{18}$ BRASIL. Lei $\mathrm{n}^{\circ} 10.406$, de 10 de janeiro de 2002. Institui o Código Civil. 2002. Disponível em: http://www.planalto.gov.br/ccivil_03/leis/2002/L10406.htm. Acesso em 03 set. 2019.
} 


\section{II - os que, por enfermidade ou deficiência mental, não tiverem o necessário discernimento para a prática desses atos; \\ III - os que, mesmo por causa transitória, não puderem exprimir sua vontade.}

O Código entendia que os menores de 16 anos não possuíam desenvolvimento intelectual apto para reger a sua vida o que tornava nulo quaisquer atos por eles praticados. Esse preceito é a única hipótese que permanece com a introdução do Estatuto, o que será demonstrado nos capítulos seguintes. Já no inciso II estabelecia hipóteses de saúde mental que afetassem o discernimento para os atos da vida civil. E, ainda, no inciso III, reconhecia causas que viessem privar, provisoriamente, a manifestação da vontade no momento da prática de atos civis.

Por sua vez, as hipóteses de incapacidade relativa estavam expressas, originariamente, no artigo $4^{\mathrm{o}}$ do Código Civil ${ }^{19}$, na seguinte forma:

\footnotetext{
Art. $4^{\circ}$ São incapazes, relativamente a certos atos, ou à maneira de os exercer: I - os maiores de 16 (dezesseis) e menores de 18 (dezoito) anos;

II - os ébrios habituais, os viciados em tóxicos e os que, por deficiência mental, tenham o discernimento reduzido;

III - os excepcionais, sem desenvolvimento mental completo;

IV - os pródigos.
}

Aos menores de 18 anos e maiores de 16 anos, o ordenamento jurídico previa (o que se manteve com a nova legislação) a possibilidade de praticar diversos atos, mas respondendo por aqueles em que houver praticado ilicitamente. Além da possibilidade de ter reconhecida a sua capacidade para a prática dos atos civis, antecipadamente, por força de sua emancipação. Os incisos II e III estabeleciam situações dos quais as pessoas "por não terem perfeito conhecimento da realidade e dos fatos, ficam tolhidas de exercer autonomamente os atos da vida civil, necessitando de assistência." 20

Aos ébrios habituais e aos viciados em tóxicos era disciplinada a avaliação probatória, inclusive através de interrogatório pelo juiz a fim de definir a incapacidade. Ademais, a diferença que se trazia entre deficiência

\footnotetext{
${ }^{19}$ BRASIL. Lei no 10.406 , de 10 de janeiro de 2002. Institui o Código Civil. 2002. Disponível em: http://www.planalto.gov.br/ccivil 03/leis/2002/L10406.htm. Acesso em 03 set. 2019.

${ }^{20}$ VENOSA, Silvio de Salvo. Direito civil: parte geral. São Paulo: Atlas S.A, 2013.
} 
mental e os excepcionais, residia na limitação mental congênita - aos deficientes mentais - e, adquiridas - aos excepcionais. Independente da origem da limitação, a incapacidade era reconhecida judicialmente através do processo de interdição.

A fim de completar a apresentação do referido artigo, cabe referência ao pródigo mesmo não sendo objeto deste estudo, sendo todo aquele que gasta desordenadamente, dilapidando os seus bens tendo caráter de proteção dos interesses da família.

\subsection{RESPALDO LEGISLATIVO NA ÁREA DA EDUCAÇÃO}

O acesso à educação e o aparato educacional fornecido de forma municipal, estadual e particular, são as fontes basilares da sociedade, e funcionam como a alçada para o desenvolvimento do país. No que tange ao acesso à educação, a Lei no $13.146 / 2015^{21}$ discorre em seu artigo $27^{\circ}$, que:

\footnotetext{
"A educação constitui direito da pessoa com deficiência, assegurado sistema educacional inclusivo em todos os níveis e aprendizado ao longo de toda a vida, de forma a alcançar o máximo desenvolvimento possível de seus talentos e habilidades físicas, sensoriais, intelectuais e sociais, segundo suas características, interesses e necessidades de aprendizagem.

Parágrafo único. É dever do Estado, da família, da comunidade escolar e da sociedade assegurar educação de qualidade à pessoa com deficiência, colocando-a a salvo de toda forma de violência, negligência e discriminação."

Pautando pela inclusão, vislumbra-se a conjunção com o máximo de desenvolvimento possível do indivíduo, pois a inclusão significa fornecer educação de qualidade a cada um independente de suas particularidades dentro do ambiente escolar, de forma que os procedimentos educacionais, devem ser igualitários, assim como os atendimentos fornecido a todos os estudantes.
}

Desta forma, o que rege a órbita da palavra "inclusão" está expressamente dialogada no conceito de que a sociedade deve ser adaptada as pessoas, a fim de que as escolas constituam ambientes capazes de fornecer o desenvolvimento em sua totalidade a todos os estudantes, sem exceções. As medidas capazes de expandir tal desenvolvimento giram em

\footnotetext{
${ }^{21}$ BRASIL. Lei No ${ }^{\circ}$ 13.146/2015. Lei Brasileira de Inclusão da Pessoa com Deficiência. Disponível em: http://www.planalto.gov.br/ccivil 03/ ato2015-2018/2015/lei/113146.htm. Acesso em 03 set. 2019.
} 
torno da acessibilidade. A Lei $\mathrm{n}^{\mathrm{o}} 7.853$ de 1989 estabelece, em seu artigo $8^{\circ}$ como crime a recusa em aceitar matriculas de pessoas portadoras de qualquer tipo de deficiência ${ }^{22}$, nos seguintes termos:

\footnotetext{
Art. $8^{\circ}$ Constitui crime punível com reclusão de 2 (dois) a 5 (cinco) anos e multa:

I - recusar, cobrar valores adicionais, suspender, procrastinar, cancelar ou fazer cessar inscrição de aluno em estabelecimento de ensino de qualquer curso ou grau, público ou privado, em razão de sua deficiência;
}

Cada deficiência deve ser analisada a partir de sua especificidade, a fim de que sua diversidade seja valorada para que as crianças tanto como os adolescentes aumentem seu desempenho, sem necessariamente partir de um tratamento genérico ou comparativo, desta forma o ensino inclusivo pode alcançar sua égide no sistema educacional.

\section{O AUTISMO (TEA)}

O Autismo, ou o Transtorno do Espectro Autista (TEA), termo vigente no DSM-5, é uma desordem do desenvolvimento caracterizada pelo déficit de comunicação verbal/não verbal, interação social/ emocional e comportamentos/interesses/atividades repetitivas, manifestadas precocemente principalmente entre 12 e 24 meses, com prejuízo social e ocupacional, e não explicados por deficiência intelectual (retardo mental) ou atraso global do desenvolvimento.

O TEA engloba os antigos termos e subtipos de autismo, como: autismo infantil, autismo de Kanner, autismo de alta performance, autismo atípico, desordem invasiva do desenvolvimento, desordem desintegrativa da infância, e síndrome de Asperger. ${ }^{23}$

Ademais, a deficiência supracitada afeta principalmente as condutas pessoal-social e de linguagem do neurodesenvolvimento infantil. Encontram-se prejudicados os marcos/habilidades referentes a comunicação verbal, comunicação não verbal e a Interação social e

\footnotetext{
22 BRASIL. $\quad$ Lei $\quad \mathbf{n}^{\mathbf{0}}$. $\quad \mathbf{7 . 8 5 3 . 1 9 8 9}$. Disponível <http://www.planalto.gov.br/ccivil_03/leis/L7853.htm\#targetText=Disp\%C3\%B5e\%20sobre\%20o\% 20 apoio $\% 20 \% \mathrm{C} 3 \% \mathrm{~A} 0$ s, crimes $\% 2 \mathrm{C} \% 20 \mathrm{e} \% 20 \mathrm{~d} \% \mathrm{C} 3 \% \mathrm{~A} 1 \% 20$ outras $\% 20$ provid\%C3\%AAncias.> Acesso em 03 set. 2019.

${ }^{23}$ AMERICAN PSYCHIATRIC ASSOCIATION. Manual diagnóstico e estatístico de transtornos mentais. Tradução: Maria Inês Corrêa Nascimento. 5. ed. Porto Alegre: Artmed, 2014. p. 53.
} 
emocional que consiste na falha em compartilhar sentimentos e pensamentos (ex.: ausência do comportamento de imitação entre os pares da mesma idade), diminuição do interesse em brincar junto com pares (podem até se aproximar de adultos ou crianças menores), preferência por estar sozinho, insistência em brincar da mesma forma, assim como o interesse ao comportamento, hábitos repetitivos. ${ }^{24}$

Há de se salientar que o TEA pode afetar $1 \%$ da população, sendo quatro vezes mais frequente no sexo masculino. ${ }^{25}$

Um dos tratamentos do autismo é feito através de terapia cognitivo-comportamental. A terapia envolve treinamento de comportamentos sociais, atividades de imitação, integração com outras crianças e comunicação (verbal e não verbal) ${ }^{26}$, enfatizando a importância do portador de TEA em uma sala de aula, assim como a educação e treinamento dos pais e profissionais de ensino sobre técnicas de comportamento são fundamentais para o máximo desenvolvimento do autista no ambiente escolar.

\subsection{NCLUSÃO EDUCACIONAL AOS PORTADORES DE AUTISMO ANTES DA LEI № 13146/2015}

Após a Constituição da Republica de 1988, e a adoção do princípio da dignidade humana, todos os portadores de algum tipo de deficiência passam a ser titulares de certas garantias, inclusive o direito ao acesso à educação. Assim, é necessário citar os artigos 205 e 206, inciso I, os quais respectivamente impõem que a educação, é um direito de todos, e deve assegurar a igualdade no que diz respeito ao acesso em escolas.

Ademais, a questão principal é enfatizar o acesso igualitário dos deficientes na área educacional. Sancionada em 1989, a Lei $\mathrm{n}^{\circ} 7.853$, conforme seu art. $2^{\circ}$, inciso I, define que:

“(...) na área da educação:

a) a inclusão, no sistema educacional, da Educação Especial como modalidade educativa que abranja a educação precoce, a préescolar, as de $1^{\circ}$ e $2^{\circ}$ graus, a supletiva, a habilitação e reabilitação profissionais, com currículos, etapas e exigências de diplomação próprios;

\footnotetext{
${ }^{24}$ BURNS. Dennis Alexander Rabelo. Tratado de Pediatria. 4. ed. São Paulo: Manole. 2017. pg. 270. ${ }^{25}$ AMERICAN PSYCHIATRIC ASSOCIATION. Manual diagnóstico e estatístico de transtornos mentais. Tradução: Maria Inês Corrêa Nascimento. 5. ed. Porto Alegre: Artmed, 2014. p. 55.

${ }^{26}$ Idem. p. 57.
} 
b) a inserção, no referido sistema educacional, das escolas especiais, privadas e públicas;

c) a oferta, obrigatória e gratuita, da Educação Especial em estabelecimento público de ensino;

d) o oferecimento obrigatório de programas de Educação Especial a nível pré-escolar, em unidades hospitalares e congêneres nas quais estejam internados, por prazo igual ou superior a 1 (um) ano, educandos portadores de deficiência;

e) o acesso de alunos portadores de deficiência aos benefícios conferidos aos demais educandos, inclusive material escolar, merenda escolar e bolsas de estudo;

f) a matrícula compulsória em cursos regulares de estabelecimentos públicos e particulares de pessoas portadoras de deficiência capazes de se integrarem no sistema regular de ensino; ${ }^{27}$

Tencionando direitos inerentes aos cidadãos, como discorrido a cima a oferta obrigatória e gratuita, da Educação Especial em estabelecimento público de ensino. O enfoque está na criminalização de posturas abusivas e preconceituosas, como exigir valores adicionais na matrícula do aluno na escola e até mesmo em recusar, suspender, adiar, cancelar ou extinguir a inscrição de um estudante por causa de sua deficiência, seja em instituto público ou privado.

Assim, foi criada a Lei $n^{\circ} 12.764 / 2012$, e o seu artigo $7^{\circ}$ discorre que:

O gestor escolar, ou autoridade competente, que recusar a matrícula de aluno com transtorno do espectro autista, ou qualquer outro tipo de deficiência, será punido com multa de 3 (três) a 20 (vinte) salários-mínimos. ${ }^{28}$

Desta forma, fica ampliado o conjunto de direitos elucidados pela Constituição de 1988, enfatizando a vedação da recusa de matrícula escolar aos portadores de TEA com a impugnação de sanções para quem incorrer nesse ato discriminatório, fomentando e enriquecendo, portanto, a força da Lei $n^{\circ} 13.146 / 2015$.

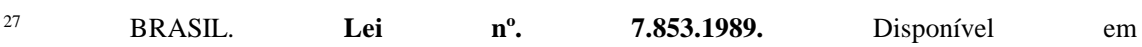
<http://www.planalto.gov.br/ccivil_03/leis/L7853.htm\#targetText=Disp\%C3\%B5e\%20sobre\%20o\% 20 apoio $\% 20 \% \mathrm{C} 3 \% \mathrm{~A} 0$ s, crimes $\% 2 \mathrm{C} \% 20 \mathrm{e} \% 20 \mathrm{~d} \% \mathrm{C} 3 \% \mathrm{~A} 1 \% 20$ outras $\% 20$ provid\%C3\%AAncias.> Acesso em 03 set. 2019.

${ }^{28}$ BRASIL. Lei no 12.764. 2012. Disponível em < http://www.planalto.gov.br/ccivil_03/_Ato20112014/2012/Lei/L12764.htm > Acesso em 03 set. 2019.
} 


\title{
AS FALHAS NA LEI N.13.146/15 NA INSERÇÃO DOS PORTADORES DE TEA NA AREA EDUCACIONAL
}

O principal problema gira em torno da criação da lei, que visa amparar de uma forma geral as pessoas com deficiência. Essa generalidade é prejudicial, uma vez que cada desigual deveria ser tratado desigualmente, no sentido de que um autista tem necessidades diferentes de um cadeirante, tornando o rol de auxilio que deve ser fornecido diferente também.

Ao se aplicar um protocolo geral para indivíduos diferentes, encontramos pormenores que geram a inviabilização do principal quesito da lei, que é assegurar o máximo desenvolvimento desse indivíduo.

Como a legislação em tela, não visualiza uma das principais caraterísticas do TEA, que é a dificuldade de aceitar mudanças, ela se torna falha. Na aplicação do art. 28, incisos II, da Lei $n^{\circ} 13.146 / 2015$ não se visualiza o aprimoramento que é citado nos sistemas educacionais para atender as demandas de um autista, faltando uma legislação própria dentro do Sistema de Ensino para que os portadores do TEA não tenham que lidar com mudanças anuais, que são comuns aos alunos que todo ano trocam de espaço físico na escola e de professores.

O relato da genitora Musa Vila Nova, que possui um filho autista de seis anos, denuncia que:

\begin{abstract}
A principal dificuldade que enfrentou ao colocar Júlio para estudar foi fazer a escola entender que, mesmo sem um grau de autismo severo, a criança necessitava de um acompanhamento terapêutico. Além disso, relatou sentir falta de material pedagógico especializado e de cursos de capacitação para os professores e demais profissionais que irão conviver com essas crianças. Assim, inicialmente, tive dificuldade em colocar um auxiliar terapêutico lá dentro, mesmo eu pagando. Tenho dificuldade de eles entenderem que a criança não pode estar em uma sala com muitos alunos porque o barulho incomoda muito. Dificuldade de não existir nenhum material especial elaborado pela escola para aprendizagem deles porque eles são visuais e não aprendem como as demais crianças. ${ }^{29}$
\end{abstract}

A palavra chave "inclusão" se torna avulsa em meio a uma regressão do aluno com deficiência, o que gera, em tese uma exclusão, ante ao fato que são ignoradas as principais características do TEA, como relatado acima em que Júlio tem facilidade de aprender por imagens, e não

\footnotetext{
${ }^{29}$ AGÊNCIA SENADO. Lei Brasileira de Inclusão completa um ano com avanços na educação. 2016.

Disponível em: < https://www12.senado.leg.br/noticias/materias/2016/07/01/lei-brasileira-deinclusao-completa-um-ano-com-avancos-na-educacao > Acesso em 03 set. 2019.
} 
são utilizados métodos desse tipo por sua instituição de ensino, assim os bons fundamentos da legislação não se tornam eficientes na pratica.

\subsection{AS SOLUÇÕES TRAZIDAS FRENTE AS GENERALIDADES DA LEGISLAÇÃO}

$\mathrm{O}$ apontamento central seria viabilizar tanto uma estrutura singular para cada deficiência como uma de maneira geral para que assim se supram as lacunas existentes, e de forma mais intrínseca viabilizar treinamentos específicos aos educadores, profissionais de apoio e alunos para saberem como lidar com cada situação que possa ocorrer durante um processo de inserção de uma pessoa com deficiência numa sala de aula, além do amparo familiar e estatal. Ademais, outra questão que deveria ser levantada é conscientização, a questão cultural em volta da discriminação, deve ser tratada de forma consciente pelo Estado.

Portanto, ocorre que a adaptação deve incidir na instituição de ensino, e não no aluno portador de TEA, ressalta-se a importância das escolas, do estado e de todos os cidadãos em terem uma atitude de mudança no olhar, na perspectiva de como tratar um deficiente, sucumbindo a necessidade de ocorrer um arranjo de medidas conjuntas na pratica para a efetivação da Lei $n^{\circ}$ 13.146/2015.

\section{CONSIDERAÇÕES FINAIS}

A intenção almejada pela Lei N. 13146/2015 tem boa titularidade, visto que abrange a garantia a acessibilidade, a educação a saúde aos portadores de deficiência, e assim se funda na Convenção sobre os Direitos das Pessoas com Deficiência, além de tecer o critério de inclusão em nosso ordenamento jurídico e estabelecer um atendimento diferenciado principalmente aos portadores de TEA (Autismo).

A resguarda educacional permitida pela legislação em tela, vislumbrou as três esferas educacionais do país, sendo municipal, federal e particular, enfatizando a atuação de forma a valorizar o máximo desenvolvimento dos alunos, revestida de uma educação de qualidade independente da especificidade de cada deficiência. 
Assim, o ponto inicial de todos os educadores e instituições escolares, se tangem no sentido de que não são os portadores de deficiência que devem se adaptar para ser incluídos, e sim a sociedade brasileira que deve se adaptar as particularidades de cada deficiência. Pontuada pela Lei $\mathrm{n}^{\mathrm{o}} 7.853$ de 1989 , ser crime a recusa em aceitar inscrições de portadores de qualquer tipo de deficiência.

$\mathrm{O}$ autismo ou TEA, consiste em uma condição geral para um grupo de desordens de desenvolvimento do cérebro manifestadas precocemente principalmente dos 12 aos 24 meses de idade, esses distúrbios se caracterizam pela dificuldade na comunicação verbal e não verbal, deficit na interação social e emocional, com incidência de comportamentos repetitivos e a dificuldade de se adaptar de forma rápida a mudanças.

Antes da Lei ${ }^{\circ}$ 13.146/2015 a Constituição Federal de 1988, trazia princípios basilares de alguns direitos aos portadores de deficiência, inclusive o direito à educação, juntamente com a Lei no 7853/1989, a qual já trazia fundamentos expressos referente ao sistema educacional inclu sivo.

Outrora, a Lei $\mathrm{n}^{\mathrm{o}} 13.146 / 2015$ tenha um caráter idealístico totalmente fundada nos princípios inerentes dos Direitos Humanos, a legislação possui obscuridades no tocante de que veste uma roupagem geral e não individualiza cada deficiência de forma a enxerga-las de forma especifica dentro da necessidade de cada cidadão.

Posto que uma criança portadora do Autismo necessita de atendimentos e procedimentos especiais, visto que possui dificuldade em lidar com mudanças, e de comunicação verbal e não verbal.

Assim, a palavra basilar se torna perdida em meio ao decaimento do aluno com deficiência, que em suma provoca o contrário do pretendido pela palavra inclusão, ou seja, sua exclusão, diante da ignorância das necessidades principais de um portador de TEA. Gerando a utopia da lei, pelo fato de na prática não ocorrer as postulações expressas na norma.

Contudo, se uma estrutura de maneira singular se tecer de forma eficiente para suprir as obscuridades legislativas, posto que os educadores, o Estado, os alunos e os professores tivessem treinamento específico, e se adaptarem às características dos portadores de autismo, sem deixar de lado a questão cultural, trabalhando políticas anti-discriminatórias com toda a população, a educação e o pretexto da Lei n ${ }^{\circ}$ 13.136;/2015 atingiriam sua ascensão e a palavra inclusão realmente deixaria o plano normativo e atingiria o plano material, da prática. 


\section{REFERÊNCIAS BIBLIOGRÁFICAS}

AGÊNCIA SENADO. Lei Brasileira de Inclusão completa um ano com avanços na educação. 2016. Disponível em: < https://www12.senado.leg.br/noticias/materias/2016/07/01/lei-brasileira-deinclusao-completa-um-ano-com-avancos-na-educacao > Acesso em 03 set. 2019.

ALMEIDA, João Alberto de; SOUZA BRITO, Thiago Carlos de. O princípio da segurança jurídica e suas implicações na relativização da coisa julgada. Disponível em: https://www.direito.ufmg.br/revista/index.php/revista/article/viewFile/130/121 . Acesso em 03 ago. 2019.

AMARAL, F. Direito civil: introdução. Rio de Janeiro: Renovar, 2003.

AMERICAN PSYCHIATRIC ASSOCIATION. Manual diagnóstico e estatístico de transtornos mentais. Tradução: Maria Inês Corrêa Nascimento. 5. ed. Porto Alegre: Artmed, 2014. p. 53.

ANDRADE, André Gustavo Corrêa de. O princípio fundamental da dignidade humana e sua concretização judicial. Disponível em:

http://www.tj.rj.gov.br/institucional/dir_gerais/dgcon/pdf/artigos/direi_const/o_pr. Acesso em 03 set. 2019.

BRASIL. Lei $\mathrm{n}^{\circ}$ 10.406, de 10 de janeiro de 2002. Institui o Código Civil. 2002. Disponível em: http://www.planalto.gov.br/ccivil_03/leis/2002/L10406.htm. Acesso em 03 set. 2019.

BRASIL. Lei no 12.764. 2012. Disponível em < http://www.planalto.gov.br/ccivil_03/_Ato20112014/2012/Lei/L12764.htm > Acesso em 03 set. 2019.

BRASIL. Lei Nº 13.146/2015. Lei Brasileira de Inclusão da Pessoa com Deficiência. Disponível em: http://www.planalto.gov.br/ccivil_03/_ato2015-2018/2015/lei/113146.htm. Acesso em 03 set. 2019.

BRASIL. Lei no . 7.853.1989. Disponível em

BURNS. Dennis Alexander Rabelo. Tratado de Pediatria. 4. ed. São Paulo: Manole. 2017. pg. 270.

GUTIERREZ SOBRINHO, Emílio. Neoconstitucionalismo: apontamentos teóricos. Revista Jus Navigandi, ISSN 1518-4862, Teresina, ano 17, n. 3319, 2 ago. 2012. Disponível em: https://jus.com.br/artigos/22345/aspectos-teoricos-do-movimento-neoconstitucional Acesso em 03 set. 2019.

LEITE, Flávia Piva Almeida. A Convenção sobre os Direitos das Pessoas com Deficiência: Amplitude Conceitual. Revista de Direito Brasileira. RDBras, 3ª edição, 2012, p. 36.

MARTINS, S. P. O Estatuto da Pessoa com Deficiência e as alterações jurídicas relevantes no âmbito da capacidade civil. Revista dos Tribunais, v. 974, p. 225-243, dez. 2016.

MENDES, Gilmar Ferreira; COELHO, Inocêncio Mártires; BRANCO, Paulo Gustavo Gonet. Curso de Direito Constitucional. 4. ed. São Paulo: Saraiva, 2009. 
SASSAKI, Kazumi. Convenção sobre os Direitos das Pessoas com Deficiência Comentada. 2008. p. 84. Disponível em: <https://www.governodigital.gov.br/documentos-earquivos/A\%20Convencao\%20sobre \%20os\%20Direitos\%20das\%20Pessoas\%20com\%20Deficiencia \%20Comentada.pdf> Acesso em 03 set. 2019.

VENOSA, Silvio de Salvo. Direito civil: parte geral. São Paulo: Atlas S.A, 2013. 